\title{
Studying the behaviour and sensory ecology of marine mammals using acoustic recording tags: a review
}

\author{
Mark Johnson ${ }^{1, *}$, Natacha Aguilar de Soto ${ }^{2}$, Peter T. Madsen ${ }^{3}$ \\ ${ }^{1}$ Applied Ocean Physics \& Engineering Dept., Woods Hole Oceanographic Institution, Woods Hole, Massachusetts 02543, USA \\ ${ }^{2}$ BIOECOMAC, Dept. of Animal Biology, University of La Laguna, Canary Islands, Spain \\ ${ }^{3}$ Zoophysiology, Dept. of Biological Sciences, University of Aarhus, Aarhus, Denmark
}

\begin{abstract}
Many marine animals use sound passively or actively for communication, foraging, predator avoidance, navigation, and to sense their environment. The advent of acoustic recording tags has allowed biologists to get the on-animal perspective of the sonic environment and, in combination with movement sensors, to relate sounds to the activities of the tagged animal. These powerful tools have led to a wide range of insights into the behaviour of marine animals and have opened new opportunities for studying the ways they interact with their environment. Acoustic tags demand new analysis methods and careful experimental design to optimize the consistency between research objectives and the realistic performance of the tags. Technical details to consider are the suitability of the tag attachment to a given species, the accuracy of the tag sensors, and the recording and attachment duration of the tag. Here we consider the achievements, potential, and limitations of acoustic recording tags in studying the behaviour, habitat use and sensory ecology of marine mammals, the taxon to which this technology has been most often applied. We examine the application of acoustic tags to studies of vocal behaviour, foraging ecology, acoustic tracking, and the effects of noise to assess both the breadth of applications and the specific issues that arise in each.
\end{abstract}

KEY WORDS: Acoustics $\cdot$ Tag $\cdot$ Marine mammal $\cdot$ Foraging $\cdot$ Tracking $\cdot$ Behaviour $\cdot$ Effects of noise

\section{INTRODUCTION}

Despite their role as apex predators in marine ecosystems (Bowen 1997), there are many gaps in our understanding of the behaviour, eco-physiology and conservation status of marine mammals. While some smaller species have been studied in captivity, yielding insight into their sensory capabilities and physiology, results from trained animals provide only partial information about how animals live in the wild. Field studies, on the other hand, have been hampered by a limited power to quantify the behaviour and sensory umwelt of marine animals that spend little time at the surface.

In studying free-ranging animals, the ideal is to sample sensory, locomotor and behavioural information in a way that is relevant for the animal, i.e. from the per- spective of the animal's own perception and array of sensory organs (Ropert-Coudert \& Wilson 2005). Electronic tags offer a way to approach this goal for many marine animals. Information about migratory movements, diving physiology and foraging (Kooyman 1972, McConnell \& Fedak 1996, Hindell \& Lea 1998, Baumgartner \& Mate 2003, Baird et al. 2005) has been gathered using tags that simply record the depth of the animal or transmit its position. Meanwhile, tag technology has improved considerably, and now a range of sensors can be incorporated into tags small enough to use on most marine mammals and many larger fish (Davis et al. 1999, Johnson \& Tyack 2003, Mitani et al. 2003, Miyamoto et al. 2004, Cooke et al. 2004).

Unlike other sensory cues, sound travels fast and with little attenuation in water and therefore plays a fundamental role in the lives of many marine animals 
with functions as diverse as foraging, predator detection, communication and navigation (Richardson et al. 1995, Tyack 2000, Simpson et al. 2005). For deepdiving mammals that spend much of their time in the dark, sound may be the premier means of acquiring environmental information, whether through echolocation (Au 1993) or passive listening (Schusterman et al. 2000, Gannon et al. 2005). Given this, considerable efforts have been made to record the sounds made and heard by animals in their natural environment.

Sound recordings of marine animals are usually made at a distance from the animal using sonobuoys, towed hydrophone arrays, or anchored recorders (Wiggins 2003, Mellinger et al. 2007). Such recordings can be used to deduce the occurrence or abundance of marine animals (Leaper et al. 2000, Van Parijs et al. 2002, Barlow \& Taylor 2005) and the characteristics of their calls (Møhl et al. 2003, Au \& Wursig 2004, Madsen et al. 2004). Solitary, low-frequency-vocalizing animals can be tracked at long ranges using arrays of acoustic recorders providing information about movements, repertoire and calling rates (Stafford et al. 1998). Although social and high-frequency-vocalizing animals are also readily detected in remote recordings (Oswald et al. 2003), it is difficult to track individuals for more than a few minutes as they move in and out of acoustic range, or become lost in a group of vocalizing animals. As a result, remote sound recordings often provide limited information about the behavioural dynamics of individual animals and how these relate to sound.

An alternative approach is to attach the acoustic recording device to an animal as a tag. Such a device would sample the sound environment at the animal and so provide insight into the input of a key sensory modality for many marine organisms. The high data rate required to sample sound signals means that data telemetry is impractical and data must be stored on the tag for later retrieval. Early acoustic tags (Fletcher et al. 1996, Burgess et al. 1998, Martin et al. 2005) used disc or tape drives to record sound, requiring a rigid pressure-resistant housing and a substantial power supply limiting their use to large or trained animals. A second generation of acoustic recording tags emerged when solid-state memory had become dense enough to replace moving media (Madsen et al. 2002, Burgess 2003, Johnson \& Tyack 2003). With no moving parts, the electronics can be encapsulated in resin, resulting in much smaller packages. It is now feasible to construct a tag with a recording capacity of $2 \mathrm{~d}$ at a $100 \mathrm{kHz}$ sampling rate in a volume of $50 \mathrm{~cm}^{3}(3 \mathrm{cu}$. inches). Nonetheless, and despite continual improvements in memory density, acoustic tags are shortterm devices in comparison with depth- and positionsampling tags with their lifespans of many months
(Mate et al. 2007), a fact that has fundamental implications for the way acoustic tags can be used to study animal behaviour.

The value of the data collected by an acoustic tag is amplified by adding other sensors to provide context. A variety of low-power sensors can be incorporated into an acoustic tag without greatly increasing its size, including pressure, orientation, movement and image sensors. Moreover, the sensors can be sampled synchronously with the sound recording, avoiding any ambiguity in the precedence of sounds and contextual measurements. Multi-sensor acoustic tags have proven to be a rich source of information (see 'Literature cited') on eco-physiology, foraging behaviour, bio-mechanics, biosonar, effects of noise, sound production, repertoire and behavioural use of sound by marine mammals. Most studies to date are based on small data sets from a few individuals, partly because of the short recording time of acoustic tags, but also the small number of researchers using these devices, the complexity of the data collected, and the expense, difficulty and ethical issues involved in tagging some large and protected species. As the technology and techniques to process and share data mature, more integrative studies can be expected.

In the present paper, we review some applications of acoustic recording tags in marine mammal science, exploring the potential, challenges and limitations of the tool in each application. After a brief review of the technology underpinning these devices, we examine the use of acoustic tags in studies of sound production, foraging, movement, and the effects of noise. The term 'acoustic tag' will be used for conciseness to signify an acoustic recording device, but should not be confused with the acoustic transmitting tags used to track fish, which are also termed acoustic tags (Ehrenberg \& Steig 2002).

\section{ACOUSTIC RECORDING TAG TECHNOLOGY}

In essence, an acoustic recording tag contains a hydrophone, signal acquisition hardware, microprocessor, data memory and a power source (Burgess et al. 1998, Madsen et al. 2002, Johnson \& Tyack 2003, Martin et al. 2005). The processor in the tag acquires data from the hydrophones and other sensors and streams it to memory, in some cases also performing data compression and error-detection coding. Acoustic data are typically stored in NAND flash memory, currently the highest capacity semiconductor memory technology. Flash memory is non-volatile, i.e. data are retained without power, an important attribute for a batterypowered instrument (Gill \& Brewer 2008). The density of NAND flash has doubled about every 18 mo over the 
last decade. Components with 8 GBytes (a GigaByte is $1024^{3}$ bytes) of memory are available (2009) meaning that a memory array of 64 GBytes is practical in a small tag.

A consequence of archiving data is that the tag must be recovered, necessitating either that it releases from the animal and floats to the surface or that the animal be captured for tag removal. For deep-diving animals, syntactic foam, a composite of air-filled glass spheres in an epoxy matrix, is used for flotation. The volume of foam needed is about 1- to 2-fold the volume of the electronics and battery, influencing the overall dimensions of the tag (Fig. 1) and introducing an acoustic reflector close to the hydrophones.

In the following, we provide an overview of some of the sensors used in acoustic recording tags to acquire sound and contextual information. We then consider suitable methods for attaching the tag to the animal.
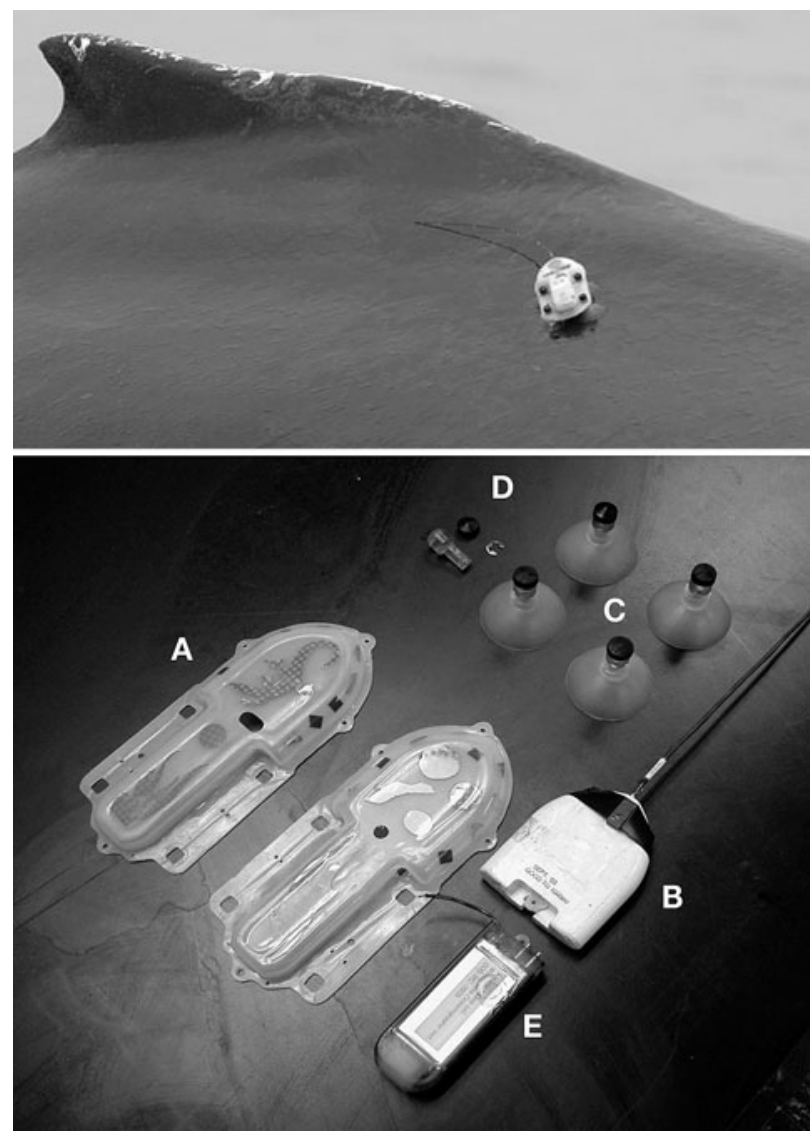

Fig. 1. Upper panel: a digital acoustic recording tag (DTAG) on a humpback whale Megaptera novaeangliae (photograph: Stellwagen Bank National Marine Sanctuary). Lower panel: internal components of a DTAG. A: plastic fairing; B: flotation; C \& D: suction cups; E: electronics module containing the battery, processor, memory and all sensors. Two spherical hydrophones are mounted in the nose of the electronics module at the bottom of the photograph

\section{Sound}

The pressure component of a sound field in water is typically sensed with a hydrophone constructed from a cylinder or sphere of piezoelectric ceramic (Rittenmyer \& Schulze 1999). The sensitivity of a hydrophone is proportional to its diameter, with a high sensitivity allowing the detection of weak sounds over the noise floor of the following preamplifier circuit. However, the ceramic must also be small compared to the wavelengths of the sounds of interest for an omnidirectional response, placing an upper limit on sensitivity. Piezoelectric hydrophones are capacitive and this property, together with the input resistance of the preamplifier, determines the low-frequency response of the recording system. Thinner hydrophones give better low-frequency responses at the expense of poor pressure tolerance. Excess low-frequency sensitivity may also cause overloading of the acquisition circuit due to vessel noise or transient sounds in the environment. Given these trade-offs, a single hydrophone will not give optimal performance over the entire frequency range of marine mammal vocalizations (at least $10 \mathrm{~Hz}$ to $200 \mathrm{kHz}$ ), and the hydrophone must be sized, to some extent, for the study species (Madsen \& Wahlberg 2007). It is essential then to report the frequency response, noise floor and directionality of acoustic tags to allow comparisons with other studies.

The output of the hydrophone is filtered by an anti-alias filter and then digitized by an analog-to-digital converter (ADC). The sampling rate must be at least twice the highest frequency of interest, although a factor of three simplifies the filter design. The number of bits used to represent each sample is chosen according to the dynamic range, defined as the difference in decibels between the most powerful sound that the tag can record without distortion (called the clipping level) and the broadband system noise floor. Acoustic tags require a high dynamic range to simultaneously capture vocalizations from the tagged animal and sounds from distant animals. The dynamic range of an ideal n-bit ADC is approximately $6 n \mathrm{~dB}$, i.e. $20 \log _{10}\left(2^{\mathrm{n}}\right)$, but in practice the noise floor of the preamplifier and converter limit this range, such that a broadband dynamic range much beyond $90 \mathrm{~dB}$ is impractical in a low-power instrument, irrespective of the ADC resolution or method (Madsen \& Wahlberg 2007). This means that each sound sample can be represented in 16 bits ( 2 bytes) with negligible performance degradation for most applications and that the gain of the tag must be set carefully to optimize usage of the limited dynamic range. Sounds above the clipping level may still be used for some analyses (e.g. to count vocalizations), but will be distorted spectrally. There is then an important compromise between being able to detect weak sounds and having quality recordings of strong nearby sounds. 
One solution to the dynamic range limitation is to record sound on multiple channels, possibly from separate hydrophones, using a different gain on each channel (Martin et al. 2005). Another advantage of using multiple hydrophones is that the direction of arrival of sounds can be estimated (Akamatsu et al. 2005a, Martin et al. 2005, Johnson et al. 2006), although errors will arise due to reflection and refraction of sound around and through the tag.

Given the above, the data rate, $r$, required to represent a sound is approximately $r=2 n_{\mathrm{h}} f_{\mathrm{s}} / C \mathrm{kB} \mathrm{s}^{-1}$, where $f_{\mathrm{s}}$ is the sampling rate in kilohertz, $n_{\mathrm{h}}$ is the number of hydrophone channels, $C$ is the compression ratio $(c=1$ if compression is not used) and 16-bit samples are assumed. For a memory capacity of $g$ GBytes, the recording duration, $d$, is:

$$
d \approx 300 \mathrm{~g} / r \approx 150 c \mathrm{~g} / n_{\mathrm{h}} f_{\mathrm{s}} \text { hours }
$$

where the multiplier comes from $1024^{2} \mathrm{kB} \mathrm{GB}^{-1} \mathrm{di}$ vided by $3600 \mathrm{~s} \mathrm{~h}^{-1}$. For example, a 32-GB tag sampling 2 hydrophones at $200 \mathrm{kHz}$ will have a duration of $12 \mathrm{~h}$ without compression, while the same tag sampling 1 hydrophone at $48 \mathrm{kHz}$ will record for over $4 \mathrm{~d}$ if battery power is sufficient. As memory capacity increases, battery capacity increasingly becomes the factor limiting recording duration of low-frequency acoustic tags.

For high sampling rate tags, there is a clear benefit in compressing sound data to increase recording time. The digital tag (DTAG; Johnson \& Tyack 2003) uses loss-less compression based on the Shorten algorithm (Robinson 1994), achieving an average compression ratio of $c=3$. Higher compression ratios are possible with lossy compression algorithms such as MP3 (e.g. $c=8$ ), but these introduce artefacts in the recording that may reduce the value of the data (Liu et al 2008). Another approach is to record non-continuously, e.g. on a schedule or when an event is detected by other sensors. It is also possible to detect specific types of sounds and just record the time at which these sounds occur (Akamatsu et al. 2005a, Blomqvist \& Amundin 2004). A down-side of these approaches is the potential to miss weak or unanticipated sounds.

Both commercial and free software programs are available for examining the acoustic data collected by tags (e.g. XBAT, Rainbow Click, Ishmael, Audacity). Analysis of acoustic data is nonetheless often time-consuming, due to the wide frequency and dynamic range of sounds in the marine environment. Automatic analysis tools are helpful, but require supervision to ensure consistent performance as the ambient noise fluctuates. Currently, there are few software programs capable of integrating sound data with other sensor streams, and the combined visualization of multi-sensor data remains a challenging task (Ware et al. 2006).

\section{Position and orientation}

Of the many sensors that could be integrated in an acoustic recording tag, position, movement and orientation sensors have received the most attention (Davis et al. 1999, Johnson \& Tyack 2003, Mitani et al. 2003, Zimmer et al. 2003, 2005c, Miller et al. 2004a,b). The ability to say where an animal is and how it moves while producing or hearing a sound is of fundamental value in studies of foraging, social behaviour and responses to sound. Six parameters are needed to represent the position and orientation of a marine animal, namely latitude, longitude, depth, pitch, roll and heading. An additional parameter, swim speed, can be derived from position measurements, but can be measured independently with greater resolution (Blackwell et al. 1999, Shepard et al. 2008). The accuracy and temporal resolution required in each of these parameters depends on the objectives of the study. Here we review briefly the capabilities and practical limitations of position and orientation sensors to provide a basis for evaluating how these data can aid in the interpretation of on-animal acoustic recordings. Ways in which the sounds recorded by an acoustic tag can themselves aid in tracking animals will be discussed in a later section.

Depth and orientation can be measured in a tag with resolution sufficient to capture individual fluke strokes using pressure, acceleration and magnetic field sensors (Johnson \& Tyack 2003, Mitani et al. 2003). The orientation measured is that of the tag, and must be corrected for the position of the tag on the animal to obtain the animal's orientation (Johnson \& Tyack 2003). For some attachment methods, the initial position of the tag may be uncertain, and the tag may move on the animal during deployment, resulting in estimates of the animal's orientation that are precise, but that may have poor accuracy.

An animal at the sea surface can be positioned visually or by using satellite-based tracking (i.e. ARGOS or the global positioning system [GPS]). New methods of GPS post-processing can yield position estimates with accuracies of better than $100 \mathrm{~m}$ on most surfacings of a tagged animal (MacLean 2009). However, as satellite radio signals attenuate rapidly in seawater, no global method exists for tracking animals below the surface. Two techniques commonly used to obtain relative tracks for diving animals are acoustic tracking and dead-reckoning.

\section{Acoustic tracking}

The position of a vocalizing animal can be estimated from the arrival times of sounds at an array of synchro- 
nized hydrophones positioned around the animal (Spiesberger \& Fristrup 1990, Wahlberg et al. 2001, Thode 2004). This method, termed passive tracking, requires 4 receivers for 3-dimensional positioning (Wahlberg et al. 2001), although fewer receivers can be used if the depth of the animal is measured with a tag or if there are multiple sound propagation paths, e.g. due to a surface or bottom bounce, between the source and receiver (Thode 2004). The same receivers can track multiple animals provided the sounds from each animal can be correctly identified at the receivers. Positioning errors depend on the location of the animal relative to the receivers and can increase rapidly with distance from the array (Wahlberg et al. 2001). Outages will occur when the animal is not detected at sufficient receivers to form a position. Passive tracking is most practical for odontocetes that produce echolocation sounds continuously during foraging dives. Animals that vocalize rarely can be tracked in the same way, but with the sound being produced by an acoustic transmitting tag attached to the animal (Watkins et al. 1993, Baumgartner et al. 2008). This technique, termed active tracking, is widely used in fisheries research (Ehrenberg \& Steig 2002), but has the disadvantage that a sound is produced close to the animal with the potential to disturb it (Watkins \& Schevill 1975, Kastelein et al. 2006). This problem can be overcome, at the expense of a reduced operating range, by using sounds with frequency above the hearing range of the animal when this is known. A major disadvantage of both passive and active acoustic tracking is the need to maintain receiving stations near the animal, increasing the complexity and expense of the experiment, as well as the possibility for disturbing the animal with vessel movements.

\section{Dead-reckoning}

In dead-reckoning, the track of a tagged whale is estimated between surfacings using inertial, speed and heading sensors in the tag (Wilson \& Wilson 1988, Davis et al. 1999, Johnson \& Tyack 2003, Mitani et al. 2003, Wilson et al. 2007). A dead-reckoned track is formed by integrating the estimated 3-dimensional velocity vector of the animal with respect to time. Although velocity is the integral of acceleration, accelerometers cannot be used by themselves to estimate velocity because these sensors measure both the animal's specific acceleration (the quantity required) and its orientation with respect to the gravity vector. In a conventional inertial measurement unit, orientation is derived from a set of 3 gyroscopes, and this is used to isolate the specific acceleration signal from the accelerometers (Grewal et al. 2001). While small, low- power accelerometers have been available for some time, miniature gyroscopes are only now becoming available with low enough power consumption for use in tags (Martin et al. 2005). In order to avoid gyroscopes, it is usual to assume that the animal moves in a direction given by its orientation and that this can be combined with a speed estimate to obtain the velocity vector (Wilson et al. 2007). Speed can be estimated from a dedicated sensor (Blackwell et al. 1999, Shepard et al. 2007), from the differential of the depth sensor (Zimmer et al. 2003, Aguilar Soto et al. 2008), or even from the low-frequency noise due to water flow over the tag (Goldbogen et al. 2007). However, the velocity vector so obtained contains a number of errors (Wilson et al. 2007); for example, lift and buoyancy forces are neglected, and the orientation estimate will be biased if the tag position on the animal is uncertain or if the animal accelerates (Johnson \& Tyack 2003). Because these errors are integrated in forming the dead-reckoned track, positional errors grow with time and can easily reach 100 s of meters during a long foraging dive. Thus, dead-reckoning offers fine time resolution and moderate short-term accuracy, but gives only a rough idea of the absolute position of the animal. There is considerable unexplored potential in integrating acoustic tracking and dead-reckoning to leverage the benefits of each method. Nonetheless, it is key, in using multi-sensor tags, to design studies that are robust to errors and outages in absolute orientation and position, while taking advantage of the time resolution of tag-based sensors.

\section{Tag attachment}

A critical factor determining the quantity and quality of data obtained with an acoustic tag is the way it is attached to the study animal. Because of their inherently short recording durations, dictated by memory and battery capacity, acoustic tags are seldom appropriate for use with skin-penetrating attachments designed for long-term deployments (Mate et al. 2007, Andrews et al. 2008). Suction cups are currently the only superficial attachment means for most free-swimming whales (Hooker \& Baird 2001), although harnesses and glued attachments are possibilities for other marine animals (Burgess et al. 1998, Davis et al. 1999, Martin et al. 2005, Meyer et al. 2007). For orientation-sensing tags, multiple suction cups may be necessary to minimize the relative movement of the sensors with respect to the whale (Johnson \& Tyack 2003). Instability in the attachment manifests itself as noise in the orientation signals, which can mask small movements such as body undulations during swimming. 
Tagging with suction cups is reported to provoke low-level, short-term reactions from most animals studied (Hooker \& Baird 2001, Hooker et al. 2001, Nowacek et al. 2004, Miller et al. 2009), although stronger responses have been reported for some species (Hanson \& Baird 1998, Schneider et al. 1998). Little is known about the longer term impact of suction cup tags on behaviour, movement, or skin condition, which will depend on the size of the tag (Wilson et al. 1986, Pavlov et al. 2007) and the stiffness of the cups. Irrespective of the number of cups or the shape of the tag, suction cup tags can slide on the animal or detach during high-speed swimming, breaching, or when contacted by another animal. While it can be viewed as positive that an animal is able to remove a tag that is uncomfortable, suction cups tend to be unreliable on social or acrobatic animals and on animals with poor skin condition. Few reports are available on the attachment duration of cups on any species, and few, on the factors controlling longevity, even though this information is crucial for designing tag-based studies (Hanson 2001).

\section{APPLICATIONS AND LIMITATIONS OF ACOUSTIC RECORDING TAGS}

In the following we consider 4 broad applications of acoustic recording tags to explore the potentials and challenges of this technology in studying marine mammals.

\section{Vocalizations: repertoire, characteristics and rates}

As with other animals, the sounds produced by marine mammals are rich in information. Calls can reveal the behavioural state (e.g. Weilgart \& Whitehead 1990, Tyack \& Clark 2000, Oleson et al. 2007), social grouping (Ford 1991, Weilgart \& Whitehead 1997), or gender, size, or relative location of the calling animal (Gordon 1991, Miller 2002). Calls can also indicate habitats and how they are used (Tyack et al. 2006, Watwood et al. 2006, Calambokidis et al. 2007, Aguilar Soto et al. 2008) or the location of migration pathways (Ko \& Zeh 1988). Although the calls of a few species are well known, there are major gaps in our knowledge about the relationship between vocal output and behavioural context, gender and age for most species of marine mammals in the wild (Tyack \& Clark 2000, Mellinger \& Barlow 2003). Such data are needed for the design of acoustic surveys, monitoring and mitigation (Barlow \& Gisiner 2006, Akamatsu et al. 2007, Mellinger et al. 2007). In these applications, statistical models for calling rates (or duration of silence; Miller et al. 2008) and the source parameters of calls are needed to evaluate the probability of detecting animals (Zimmer et al. 2008, Marques et al. 2009). Uncertainty about the location of critical habitats impedes the application of conservation regulations to some populations of marine mammals. If specific call types are associated with activities such as foraging, mating, or parental care, then the spatial and temporal extent of critical habitats might be determined acoustically.

Marine mammal vocalizations are usually characterized from hydrophone recordings with simultaneous visual observations to determine the species being recorded (Oswald et al. 2003, Soldevilla et al. 2008). This requires that other vocal species are not present and that sighting conditions are good, limiting the range of contexts in which repertoire can be established. For social species, it is seldom possible to identify which individual in a group is vocalizing, impeding evaluation of individual calling rates (but see Miller et al. 2004c). Acoustic recording tags offer some clear advantages for vocalization studies. If sounds recorded by the tag can be correctly attributed to the tagged animal, then the individual repertoire and calling rate can be determined for the period of time the animal is tagged. The behavioural context of vocalizations may also be inferred from the sound recording and from other sensors on the tag. There are, however, some fundamental limitations in using tags to measure call characteristics and repertoire.

The first difficulty relates to the characteristics of the sounds recorded by a tag attached to a vocalizing animal. Tags are almost invariably attached to the dorsal surface, posterior to the sound production site. Sounds recorded at this position are often very different from those that would be recorded at the same distance in front of the animal (Madsen et al. 2002, Zimmer et al. 2005b,c, Oleson et al. 2007) for several reasons. In many species, especially odontocetes, the tissues anterior to the sound source filter and beam-form the sound, leading to dramatic aspect-dependent differences in the wave form ( $\mathrm{Au} \mathrm{1993,} \mathrm{Miller} \mathrm{2002).}$ Sounds arriving at the tag bypass much of this processing, but instead must pass the skull, which attenuates high-frequency components. In addition, some lowfrequency sounds associated with sound production may couple poorly into the water, but reach the tag by tissue conduction (Zimmer et al. 2005a, Johnson et al. 2006). As a consequence, the wave form, duration, spectrum and source level of vocalizations from tagged animals, especially those with high-frequency components (i.e. with wavelength less than the cranial width), cannot be reliably determined from tag recordings (Madsen et al. 2002, Johnson et al. 2006). While some sound characteristics, e.g. the fundamental frequency (but not the harmonic structure) of tonal vocal- 
izations, are robust to these effects, broadband and directional signals such as echolocation clicks are radically altered in on-animal recordings (Fig. 2). The on-animal wave form almost certainly contains useful information about the functional anatomy of the sound production system (Madsen et al. 2002), but, for most studies, the far-field, on-axis wave form is of primary interest. One way to obtain far-field signals is to acquire sounds from a tagged animal using a remote hydrophone array (Zimmer et al. $2005 a, b, c)$ with the tag recording serving to identify sounds and their behavioural context. Alternatively, sounds from nearby conspecifics recorded by a tag may provide far-field exemplars if these can be identified unambiguously in the recording (Johnson et al. 2004, 2006).

Paradoxically, a second problem with on-animal sound recordings is that it is not always obvious which vocalizations come from the tagged animal as opposed to others nearby (Fig. 3). This is especially true for low-frequency tonal sounds for which the on-animal signals may only differ from far-field signals in terms of harmonic energy. Although the high received level of calls from the tagged animal is often a reliable indicator, strong calls may also come from a nearby conspecific (Fig. 3). The problem often can be overcome in multi-hydrophone tags by measuring the angle of arrival of each vocalization (Fig. 3; Akamatsu et al. 2005a, Johnson et al. 2006). Vocalizations from the tagged animal have arrival angles consistent with the orientation of the tag on the animal, while the arrival angle of calls from other animals vary widely as the tagged animal manoeuvres.

A third difficulty in using acoustic tags for vocal studies relates to the typically short attachment times of acoustic tags. The vocal output of an animal depends on many dynamic factors, including behavioural state (Tyack 2000), dive depth (Ridgway et al. 2001), location (e.g. Weilgart \& Whitehead 1997, Jones \& Sayigh 2002), time of day or year (e.g. Stafford et al. 2005) and group size (Mellinger et al. 2007), but little of this complexity is captured in a tag recording of a few hours. While future improvements in attachment longevity and tag capacity may alleviate this problem for some species, there is still considerable value in short tag recordings especially if these are combined with supporting observations of the gender, size class, behavioural state and context of the tagged animal (Oleson et al. 2007). The power of these data is in-
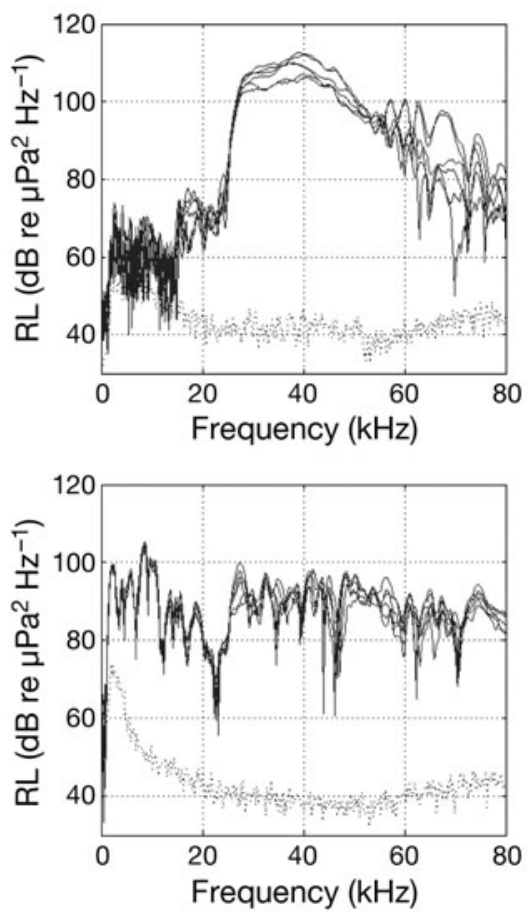

Fig. 2. Mesoplodon densirostris. Echolocation clicks recorded by digital acoustic recording tags (DTAG) on Blainville's beaked whales. Upper panels: wave form average ambient and system noise level taken $20 \mathrm{~ms}$ prior to each click

creased if they are shared between research groups to develop global, species level descriptions of sound production and habitat use (Mellinger et al. 2007).

Despite the problems inherent with on-animal sound recordings, acoustic tags have proven to be an important source of information about the sounds made by marine animals and their behavioural contexts. Acoustic tags may be especially relevant for studies of acoustic physiology, e.g. the effects of diving on sound production (Ridgway et al. 2001, Madsen et al. 2002) and for studies of call exchanges, individual-specific vocalizations and sound-mediated coordination (Tyack 2000). The addition of far-field sound recorders to these studies, to sample the acoustic context and track individual movements creates a powerful tool for studying social marine animals.

\section{Foraging}

Prey location and capture are activities of fundamental importance for any predator, but are extremely difficult to study in marine mammals. Studies of captive and trained animals can reveal some of the mechanisms and sensory capabilities used to predate 

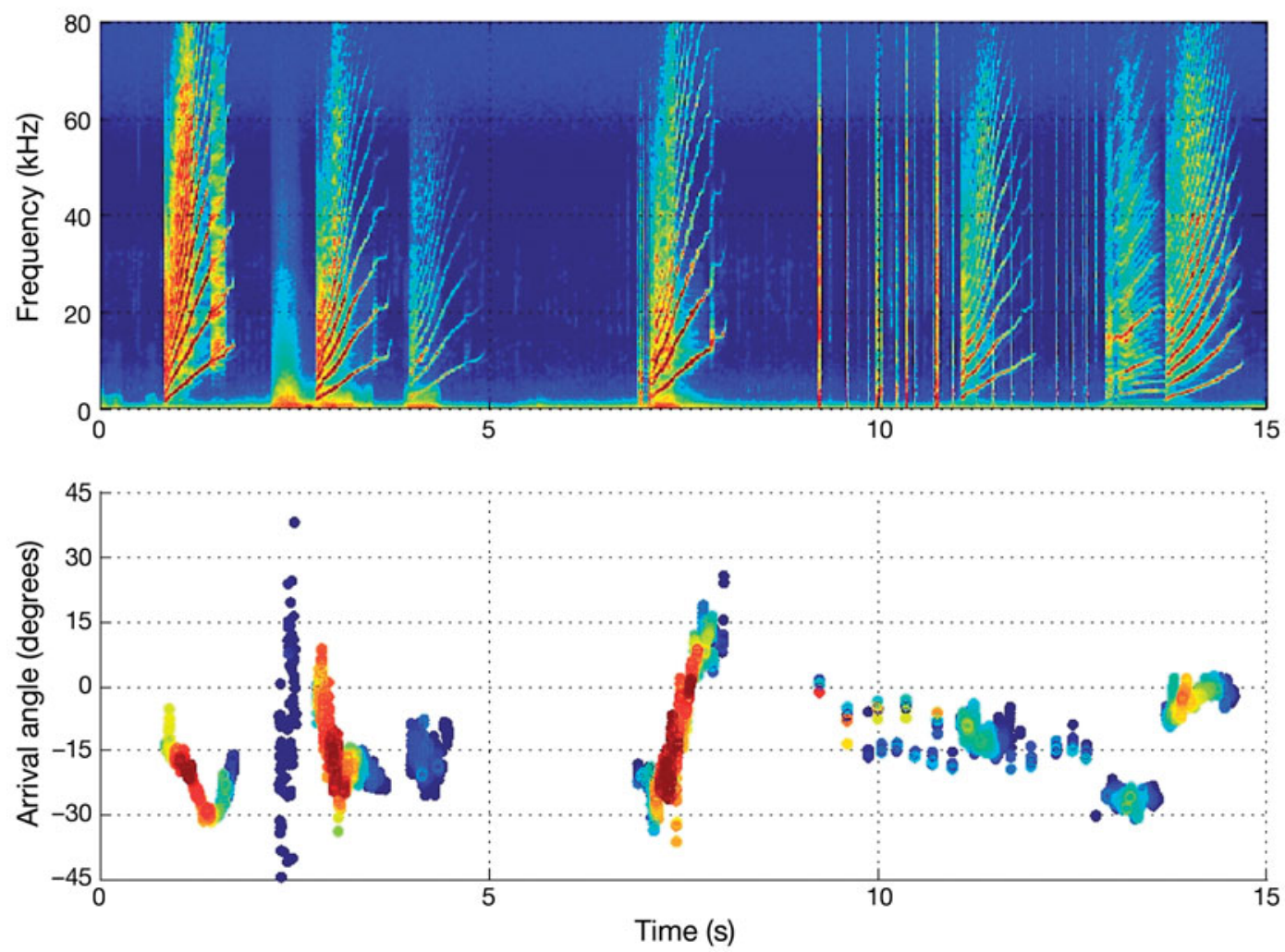

Fig. 3. Globicephala melas. Upper panel: a sequence of whistles and clicks recorded by a stereo DTAG on a short-finned pilot whale. These sounds are probably made by $>1$ animal. Lower panel: angle of arrival of each 2 ms block of sound with adequate received level for angle extraction. The level of each block is shown by colour, with red indicating a high level. The arrival angle of the strongest whistles is highly variable, indicating that these were probably not made by the tagged whale. The strong clicks at 9 to $11 \mathrm{~s}$ are likely from the tagged whale judging by their wave shape (not shown here) and their stable angle of arrival

in the wild (e.g. echolocation: $\mathrm{Au} 1993$, Houser et al. 2005; suction: Werth 2000), but these studies say little about the performance of prey location, selection and capture in the wild, or about the behaviour of prey. Many marine mammals use sound passively and/or actively to locate prey and to coordinate or compete in acquiring prey (Tyack \& Clark 2000). Some species produce sound while subduing or capturing prey, for example, tail slaps (Domenici et al. 2000), baleen rattle (Watkins \& Schevill 1976), air bubbles (Hain et al. 1982), or flow noise due to high-speed swimming (Goldbogen et al. 2007). Given this, acoustic tags provide a powerful means to study foraging in the wild.

The general strategy for analysing foraging data from acoustic tags is to look for sounds in the tag recording that are consistent indicators of the search, selection, or capture phases of foraging. The occurrence of these sounds can then be compared against measurements from other sensors to determine the context of the event, e.g. depth, orientation, location, time of day, etc. The rate of foraging events or number per dive provide an indication of foraging effort (Watwood et al. 2006) and prey encounter rate, while the number of fluke strokes between events may speak to the energy invested in pursuing and capturing prey (Williams et al. 2004, Goldbogen et al. 2007, Aguilar Soto et al. 2008). Although several baleen whale species are known to produce acoustic foraging cues, few tag-based studies exploiting these have been reported to date (Goldbogen et al. 2006, Stimpert et al. 2007). The lack of consistent vocal output in some other marine mammal species has led to an emphasis on image sensors for foraging studies (Davis et al. 1999, Calambokidis et al. 2007).

Unsurprisingly, acoustic tags have proven to be most relevant in foraging studies of echolocating odontocetes. Most odontocete species studied in the wild produce regular echolocation clicks throughout foraging dives, with occasional fast sequences of lower level clicks called buzzes (Gordon 1987, Miller et al. 1995, 2004a, Madsen et al. 2002, Johnson et al. 2004, Aguilar Soto et al. 2008). There is convincing evidence (Miller et al. 2004a, Johnson et al. 2008) that clicks and buzzes serve the same functions, namely, search and terminal homing, as do the analogous sounds produced by bats (Griffin 1958). Although it is possible that vision plays a role (Fristrup \& Harbison 2002), echolocation clicks 
and buzzes provide strong indications of when a whale is attempting to locate/select prey and attempting to capture prey, respectively (Madsen et al. 2002, Miller et al. 2004a). Because of their low source level (Madsen et al. 2005), buzzes may be difficult to detect in remote recordings for some species or when using automatic click detectors (Akamatsu et al. 2007), but they are usually straightforward to detect in acoustic tag recordings.

The immediate utility of sound-based foraging cues is exemplified by the annotated dive profiles in Fig. 4 taken from 3 species of deep-diving echolocating toothed whales. Each profile contains both deep and shallow dives. Without acoustic data, one might conclude that the 3 animals in this example demonstrated comparable behaviour, foraging in both deep and shallow prey layers, or else alternating between foraging in deep dives and resting in shallow dives. However, the sound data suggest that the foraging tactic may vary by species. While all the deep dives in Fig. 4 contain echolocation sounds, only the shallow dives of the pilot whale Globicephala melas at night (Aguilar Soto et al. 2008) and the sperm whale Physeter macrocephalus (Teloni et al. 2008) contain foraging sounds. The shallow dives of the beaked whale appear to be completely silent (Johnson et al. 2004, Tyack et al. 2006). While it is conceivable that beaked whales hunt visually during shallow dives, sensor data for these dives (Tyack et al. 2006) do not show the sudden changes in orientation usually associated with attempts to capture prey (Miller et al. 2004a). Thus, based on the limited data available, shallow dives may serve different purposes for beaked whales than for other deepdiving species, exemplifying the utility of multiple sensor modalities when interpreting animal behaviour.

Information about an echolocating predator's expectation of prey location may be embedded in the interclick-interval (ICI) of echolocation clicks, a characteristic measured reliably by acoustic tags. The ICI represents the maximum 2-way travel time to targets if these are to be unambiguously ranged (Au 1993, Akamatsu et al. 1998). Both sperm and pilot whales decrease their ICI with depth during the initial descent of foraging dives (Madsen et al. 2002, Zimmer et al. 2003, Thode 2004, Aguilar Soto et al. 2008), implying a maximum absolute search range. However, the ICI at other times is less easy to interpret. While the ICI has been found to decrease with distance to a target (a hydrophone array in this case) in some dolphin species (Au \& Benoit-Bird 2003), this pattern is not always followed by other odontocetes approaching prey in the wild (Madsen et al. 2005). The ICI during foraging dives is, in fact, highly dynamic, perhaps indicating that the distance within which the predator expects to
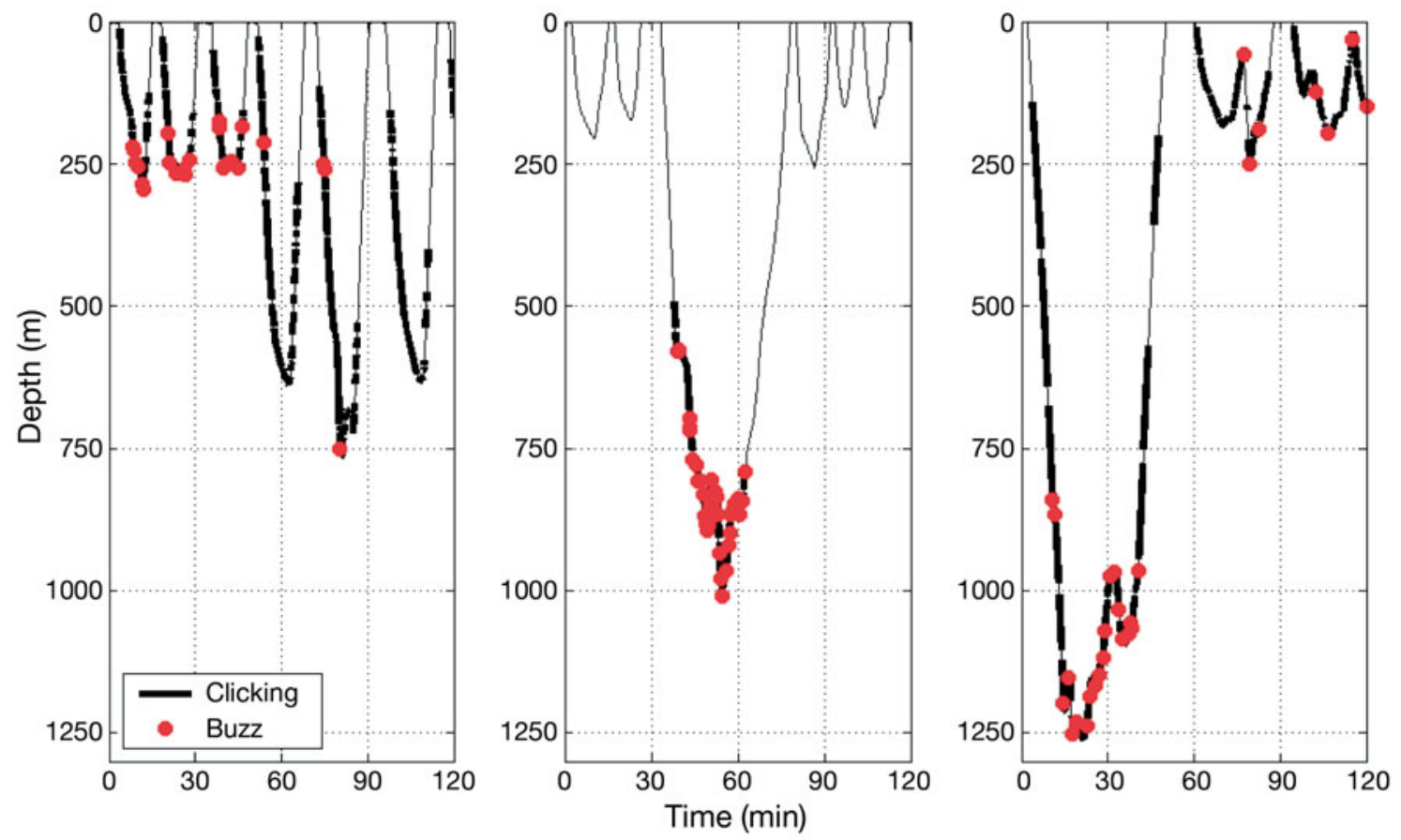

Fig. 4. Globicephala melas, Mesoplodon densirostris and Physeter macrocephalus. Dive profiles annotated with acoustic data recorded from a short-finned pilot whale (left panel), a Blainville's beaked whale (centre panel), and a sperm whale (right panel). Thick lines indicate when regular echolocation clicks are made, and red dots indicate buzzes (interpreted as prey capture attempts). All 3 whales performed both shallow and deep dives in the $2 \mathrm{~h}$ intervals, but only the pilot and sperm whales foraged in the shallow dives 
locate prey is constantly varying and that toothed whales have to deal with an auditory scene containing multiple targets (Akamatsu et al. 2005c, Madsen et al. 2005). The expectation that the ICI and orientation may be related as a whale manoeuvres to select and acquire prey invites the formation of hypotheses for studying the sensory input flow that guides motor patterns during biosonar-based foraging (Johnson et al. 2008).

Another set of inferences can be drawn from the behaviour of the predator just prior to, and during, buzzes. If buzzes represent an attempt to capture selected prey, then the predator might be expected to adopt an orientation at the onset of the buzz that favours capture of that prey type, or to manoeuvre rapidly during a buzz to chase an escaping prey. Rapid orientation changes have been found to be a consistent feature of buzzes in sperm whales (Miller et al. 2004a), and high-speed sprints are associated with some buzzes in short-finned pilot whales (Aguilar Soto et al. 2008). Although dead-reckoned tracks have poor absolute accuracy, the relative movements of a predator while foraging may say something about the spatial distribution of prey, or about their behaviour when approached (Fig. 5; Davis et al. 1999, Mitani et al. 2004). Tortuous foraging tracks with bouts of buzzes could result from encounters with patches of prey (Johnson et al. 2008) or from chasing individual elusive prey. Little is known about the prey targeted by deepdiving odontocetes; thus, the foraging behaviour of these predators is an important indirect source of information about the prey.

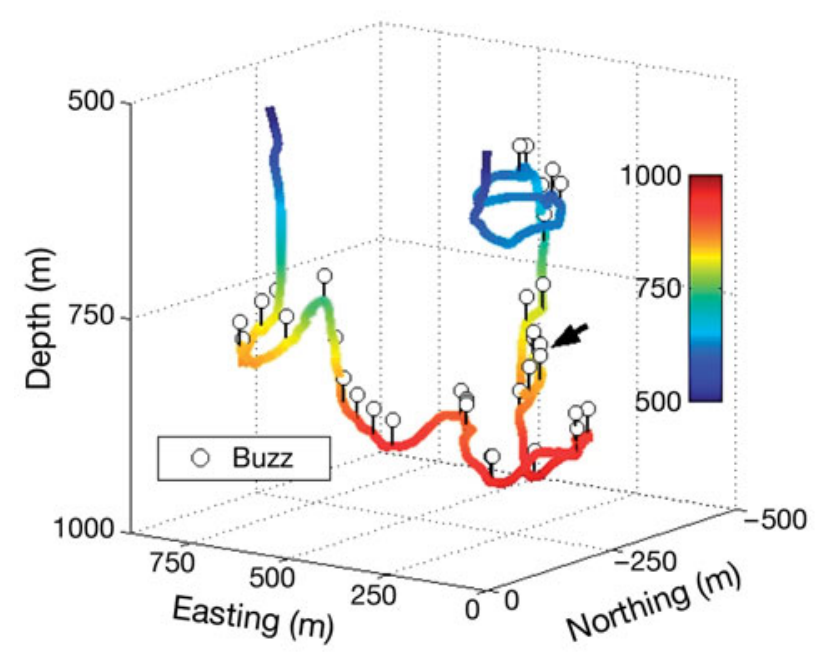

Fig. 5. Mesoplodon densirostris. Three-dimensional movements of a foraging Blainville's beaked whale estimated by deadreckoning. The large-scale plot on the left covers the entire $32 \mathrm{~min}$ of echolocation foraging during a deep dive. Although the track is unreliable in terms of distance covered, it indicates that some buzzes (echolocation sounds that are associated with prey capture attempts) occur in clusters, perhaps due to encounters with patches of prey. The right panel shows a 2 min segment of the same track, extracted at the arrow (left panel). In the right panel, the durations of buzzes are shown by wide track segments, and the pins indicate the end of each buzz. The horizontal projection of the track is also shown to demonstrate the grouping of buzzes.

The tortuous track segment associated with the buzz cluster supports the idea of a prey patch
The most detailed data on the behaviour of predator and prey have come from echoes recorded by acoustic tags on some echolocating odontocetes (Johnson et al. 2004, 2006, 2008, Madsen et al. 2005). Echoes can be visualized in acoustic tag recordings by forming stack plots, or echograms, of sound envelopes synchronized to the outgoing click as in echosounders (Fig. 6; Johnson et al. 2004). The time delay between the outgoing click and the echo, multiplied by one-half of the sound speed, gives the distance to the target. Echoes from the sea floor, as in Fig. 6, are routinely observed in tag recordings from sperm whales, pilot whales and beaked whales, with some whales nearly reaching the sea floor on some dives. The altitude of prey capture events above the sea floor and the whale's movements near the bottom may carry information about the prey they are targeting. Echoes from potential prey have, to date, only been reported from the 2 species of beaked whales that have been tagged with acoustic tags (Fig. 6; Johnson et al. 2004). Tagged beaked whales appear to ensonify many more organisms in the course of a foraging dive than they attempt to capture (Madsen et al. 2005), perhaps indicating that a large proportion of the echoic targets do not represent worthwhile prey and that the whales may use acoustic cues in a selective foraging scheme (Johnson et al. 2008). While we know little about the prey targeted by beaked whales and whether these have distinctive echo signatures (Jones et al. 2008), analysis of the general target density as a function of depth may provide information about the habitats preferred by these elusive whales (Madsen et al. 2005).

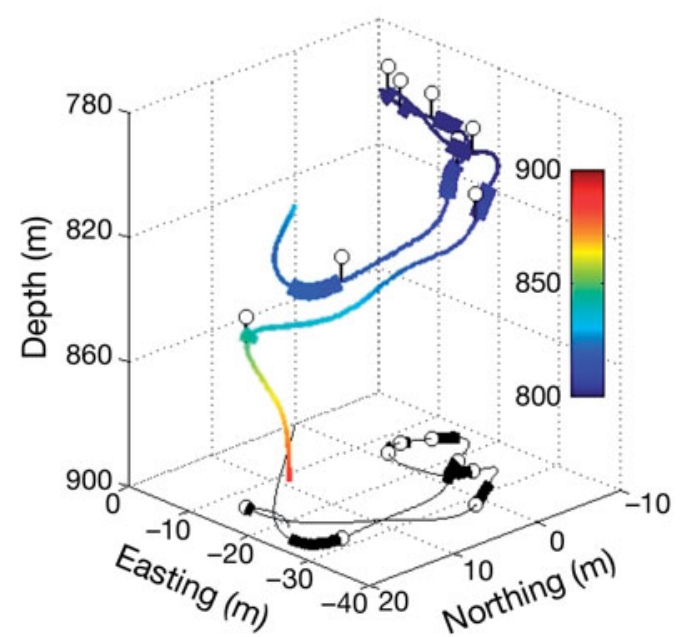



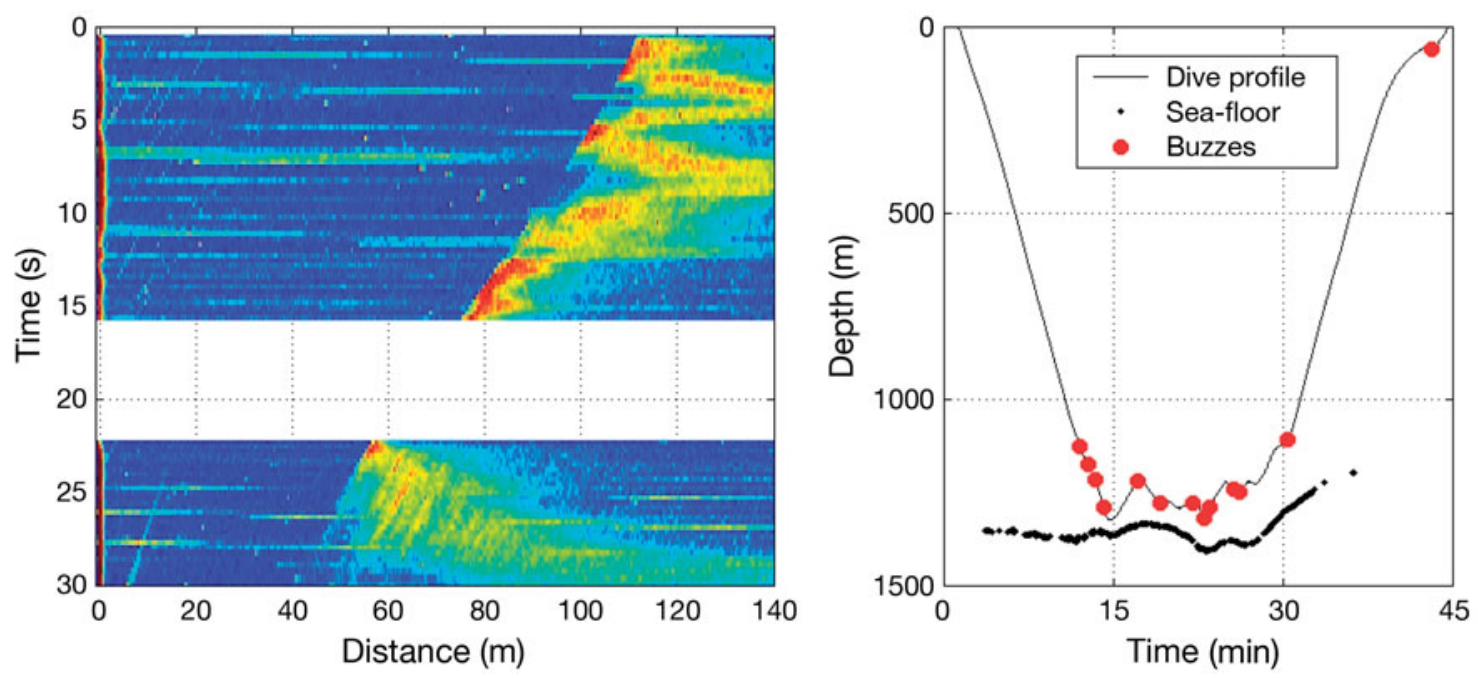

Fig. 6. Mesoplodon densirostris and Physeter macrocephalus. Left panel: echogram formed from $30 \mathrm{~s}$ of a DTAG recording from a Blainville's beaked whale at a depth of $800 \mathrm{~m}$. Evident is a strong reverberant reflection from the sea floor, which the whale is approaching at $2 \mathrm{~m} \mathrm{~s}^{-1}$. Some sequences of echoes from objects, presumably organisms, in the water are also visible, e.g. from 25 to $30 \mathrm{~s}$, at a distance of $10 \mathrm{~m}$. Clicks and buzzes from other nearby whales make the acoustic scene complex. The gap from 16 to $22 \mathrm{~s}$ is a pause in clicking. Right panel: dive profile for a sperm whale showing buzzes and the location of the sea floor acquired by forming echograms such as those in the left panel. The proximity of most of the buzzes to the sea floor may help in determining potential prey species

Studies of foraging using acoustic tags have considerable promise, especially for echolocating whales. These studies have important conservation relevance by identifying habitats in which foraging takes place, the energetic costs and rewards of predation, and the potential effects of habitat disturbances such as underwater noise and resource competition. These studies are not, however, without their limitations. The quality of on-animal sound recordings varies with the location of the tag on the animal, while the presence of sonic foraging cues in some species may depend on geographic location and the prey targeted (Deecke et al. 2005). Echoes from prey, although a powerful source of information on foraging, have been observed reliably in only a few species. Finally, in some highly vocal species, such as pilot whales, it can be difficult to determine which sounds are produced for foraging and which sounds have a predominantly social function.

\section{Tag-aided acoustic tracking}

Information about the location and movements of marine animals is essential in a variety of studies that may involve acoustic tags:

(1) Integrated prey-predator studies require the movements and foraging behaviour of a marine predator with respect to a prey field that is tracked independently (e.g. Benoit-Bird \& Au 2003, Davis et al 2007)

(2) Estimating the source level and beam pattern of vocalizations requires the distance and orientation of a tagged animal with respect to a receiving array (Zimmer et al. 2005c)

(3) Studies of habitat use with conservation applications (e.g. evaluation of the risk of ship collisions or entanglement in fishing gear) need the movements of animals with respect to the sea floor or shipping channels

(4) Sound response studies require the distance and movements of animals with respect to a sound source (Nowacek et al 2004)

(5) Studies of social interactions (e.g. allo-parental care) may need the relative locations of animals within a group.

Most of these studies require better tracking accuracy than can be achieved by dead-reckoning alone, necessitating, in most cases, some form of acoustic tracking. As outlined above, animals can be tracked acoustically without requiring a tag, providing they vocalize frequently (passive tracking; Wahlberg et al 2001). Infrequent vocalizers can be tracked if they are tagged with a sound transmitting tag (active tracking; Baumgartner et al. 2008). Here we consider how acoustic tags can aid passive and active tracking, and introduce a third tracking scheme enabled by acoustic tags: animal-relative tracking.

\section{Passive tracking}

In passive tracking, the arrival times of vocalizations at multiple receivers are used to localize the vocaliz- 
ing animal. If several animals are vocalizing, e.g. in schools of delphinids, it can be challenging to track a single animal for any length of time. An acoustic tag is helpful in post-processing to indicate vocalizations that are produced by an individual (Zimmer et al. 2005b, Ward et al. 2008). Sensors in the tag can also give the orientation of the animal at the precise time of each vocalization as needed in studies of sound source characteristics. If a sequence of positions is determined for the tagged animal, the clock offset of the tag with respect to the receivers can be estimated (Johnson et al. unpubl. data) giving the absolute production time of each vocalization. This eliminates a variable in the tracking problem, making it possible to determine the position of the animal when it is not audible at enough receivers for hyperbolic tracking (Schau \& Robinson 1987), improving the temporal resolution of the track. When the position of a tagged animal and the clock offset of the tag are established, the tag effectively becomes another receiving station able to aid in tracking other animals.

\section{Active tracking}

In active acoustic tracking, a transmitting tag normally provides the sound. The use of an acoustic recording tag in substitution for a transmitting tag allows the sound source and receivers to be transposed. Instead of transmitting from the animal to an array of receivers, the receivers can be replaced by an array of synchronized acoustic transmitters (Schmidt et al. unpubl. data). The transmissions are recorded by an acoustic tag on an animal, and their relative arrival times are extracted in post-processing of the tag recording. Hyperbolic positioning is performed as before using the differences in arrival times. To avoid ambiguity, the transmitters can produce distinct frequencies or use coded signals (Schmidt et al. unpubl. data). As with passive tracking, clock offset estimation can be used to improve tracking performance. The transposed active tracking scheme enabled by acoustic tags has some advantages over conventional active tracking using transmitter tags. The synchronized transmitters may be simpler and cheaper to produce than sound receivers, and only 1 sound recording need be processed instead of 3 or more. The sound sources are also much further from the animal than is the case with a transmitting tag, reducing the potential for disturbing the animal.

\section{Animal-relative tracking}

In some tracking studies, the data really required are the locations of an animal relative to another animal or resource as a function of time. These can be obtained by tracking each animal or resource independently and then differencing their positions to get the relative locations. However, a moderate error in each position can translate into a large error in relative location, especially if the animals and resources are closer to each other than they are to the tracking stations. An alternative approach, enabled by acoustic tags, is to extract information about relative location from the sounds arriving at a tagged animal, in effect using the same acoustic cues that are available to the tagged animal. An example of this has already been given: the use of echoes off the sea floor from echolocation clicks to determine the altitude of a tagged animal (Fig. 6). This animal-relative approach gives a more direct and precise measure than is possible by tracking the whale and measuring the bathymetry along the track line. Akamatsu et al. (2005b) used a similar method, echoes from the sea surface recorded by an acoustic tag, to deduce the beam pattern of finless porpoises. The arrival angle of sounds recorded by multichannel tags can be used to identify and track individuals in groups of echolocating whales (Akamatsu et al. 2005a, Johnson et al. 2006). Sequences of echolocation clicks from individual untagged whales can often be identified in a tag recording on the basis of consistent ICI and angle of arrival for periods of 10 s of seconds at a time (Fig. 3; Johnson et al. 2006, Akamatsu et al. 2007). The number of simultaneous click sequences is a lower limit on the number of animals in the vicinity of the tagged whale, and the relative locations of these animals might be estimable by multipath tracking.

A more accurate animal-relative measure of separation distance is possible if 2 or more vocalizing whales are tagged with acoustic tags. This technique requires that vocalizations made by one tagged whale are audible in the tags attached to the other animals. The distances between the tagged whales are derived from the times at which the same call is received on each tag. This method has been used to measure the distance between pairs of foraging sperm whales separated by up to $3 \mathrm{~km}$ with $1 \mathrm{~s}$ resolution and errors of a few percent (Johnson et al. unpubl. data). As with other animal-relative tracking methods, this method requires that the animals vocalize frequently and remain within acoustic range of each other, a convergence of events that is difficult to plan. Nonetheless, the use of acoustic tags to track groups of odontocetes and to sense features of the environment is leading to emerging application of these devices.

\section{Effects of sound}

Growing concern about the impact of humansourced sound in the marine environment has prompted the design of experiments to measure the effects of 
sound on marine organisms (Popper et al. 2003, Hildebrand 2005, Cox et al. 2006, Nowacek et al. 2007). In addition to improving the management of human activities, sound effects and playback studies can potentially uncover basic information about the audition of free-ranging animals, the way they respond to different sounds, as well as the function of their calls and how they are adjusted to changing environments.

Given the many uses of sound by animals, the effect of a sound on an individual must be a complex function of its behaviour and physical state, the received level and type of the sound, and the context in which it is experienced (Tyack et al. 2003). Multi-sensor acoustic tags facilitate sound effect studies on marine animals in several ways. (1) They offer a direct means to measure the exposure level (Nowacek et al. 2004, Madsen et al. 2006). (2) They can be used to characterize the context and some of the responses of animals to acoustic stimuli, offering a wider range of metrics than can be gleaned from surface observations or remote hydrophone recordings (Miller et al. 2009). (3) The simultaneous acquisition of sound and sensor data on the same tag eliminates doubts about the causality of exposure and changes in behaviour (Tyack et al. 2003, Johnson \& Tyack 2003). Here, we examine the opportunities for, and technical limitations of, sound effect studies based on acoustic tags, and identify the study designs that best take advantage of this technology.

\section{Measuring exposure}

Due to a lack of data about the hearing acuity of most species of marine mammals, there are no marine equivalents of the weighted measures used to quantify environmental noise exposure on humans (e.g. $L_{\text {eq }}$ or $L_{10}$; Bies \& Hanson 1996), although steps are being made in this direction (Southall et al. 2007). In lieu of standards, it has been suggested that multiple measures of the received level (RL), such as peak-peak, root mean squared and sound exposure level, be reported to facilitate comparison (Madsen 2005, Nowacek et al. 2007, Southall et al. 2007). Given the low sound levels that may elicit responses in some cases (Green et al. 1994, Nowacek et al. 2004), it is also important to report the signal-to-noise ratio (SNR) of the exposure and the presence of other sounds that could modulate the animal's response.

Both RL and SNR can be determined directly from an acoustic tag attached to the exposed animal, although there are some sources of error. Sound is attenuated as it passes through the body of an animal, leading to aspect-dependent differences in the level received by the tag and by the animal (Madsen et al. 2006). Body shadowing will be most significant at high frequencies, i.e. those with wavelengths smaller than the diameter of the animal. At low frequencies, tag recordings are usually dominated by the noise of water flowing around the tag (Burgess et al. 1998, Goldbogen et al. 2007, Insley et al. 2008), reducing the apparent SNR. Finally, all vocalizations from the tagged animal and others nearby must be excised from the acoustic record to keep them from biasing the RL estimate (Madsen et al. 2006). Despite these potential errors, tag-based RL and SNR are likely the best indications of exposure available in most situations.

\section{Measuring behavioural changes}

Multi-sensor tags provide a number of behavioural indications to use as response measures in sound effect studies. The most reliable of these relate to changes in dive profile, orientation, swimming effort and vocal output (Costa et al. 2003, Nowacek et al. 2004, Miller et al. 2009). In species for which there are consistent foraging cues, the proportion of time devoted to foraging or the number of prey capture attempts may be relevant metrics (Miller et al. 2009). Physiological measurements such as heart rate may also be relevant, but have yet to be obtained consistently on most nonpinniped marine mammals in the wild (for pinnipeds see, e.g., Fletcher et al. 1996, Hindell \& Lea 1998).

Hypotheses about sound effects are evaluated by comparing the selected behavioural proxies during exposure against a control set taken from the same individual before or after exposure, or from unexposed animals. The size and variability of the control set determine the sensitivity of the experiment and therefore the number of replicates needed to reach a conclusion for a given sound type and exposure (McGregor et al. 1992, Lipsey 1989). The behaviour of marine mammals can be highly dynamic, varying both within and across individuals and in time scales from seasonal to sub-daily, making it difficult to detect subtle responses. Some of these sources of variability are eliminated by using pre-exposure or post-exposure data from the exposed animal as the control, assuming that the experiment involves a controlled sound source (Tyack et al. 2003, Miller et al. 2009). However, this requires that the tag remains attached long enough both to avoid residual effects of tagging from influencing the pre-exposure interval and to obtain sufficient post-exposure data (Miller et al. 2009). Given the need for daylight to tag and monitor animals in exposure studies, there is a risk of a diurnal confound, as the duration of trials increases and the post-exposure intervals tend to fall in night-time hours and so to coincide with natural changes in behaviour. Considerable baseline data already exist for some species, making it 
feasible to predict by simulation the number of replicates required to detect a given level of response, as well as the most appropriate metrics to use and potential confounds, before embarking on a study (Lipsey 1989). The development of standardized communitywide data bases of behavioural data from tags would facilitate this.

Despite the range of inferences that can be drawn from multi-sensor tag data, relatively few behavioural or physiological variables are directly measured by a tag and these may reveal little about the physical state and previous history of the tagged animal or about stress-related or long-term responses to an exposure (Wright et al. 2007). As in any study of effects, while evidence may be found for a response, it is rarely possible to conclude that there was no response. Undetected responses cannot be discounted unless hypotheses are carefully defined to be testable within the sensory modalities available (McGregor 2000), but interpreting the significance of narrow hypotheses may be challenging, a problem that is compounded by the lack of context in short tag deployments. In any case, it is essential to report the full range of behavioural metrics examined, whether or not responses were detected in these.

\section{Experiment design}

Sound effect studies are termed controlled or opportunistic according to whether there is experimental control over the sound source (Tyack et al. 2003). In tag-based opportunistic studies, an animal is tagged in an area in which it may be exposed to the sound of interest (e.g. Burgess et al. 1998, Costa et al. 2003, Aguilar Soto et al. 2006). The exposure is authentic in the sense that it involves the actual sound source under real life conditions, and the expense of such studies may be relatively low. However, suitable controls may be hard to identify, requiring the use of control data from other locations, seasons, or subpopulations. Natural behaviour can vary widely with location, necessitating a large data set to detect a response, while, at the same time, introducing ambiguity in interpreting responses. Opportunistic studies may be most effective when a noise source starts de novo and animals can be tagged prior to, and following, initiation of exposure.

In controlled studies, the location and timing of the sound source are manipulated so as to expose a tagged animal with a predetermined RL and in a behavioural state for which relevant behavioural metrics are sampled by the tag. Paired designs are possible using the pre- or post-exposure behaviour of the tagged animal as a control (Tyack et al. 2003). As a result, controlled studies have a higher yield per exposure and, potentially, a higher power to detect responses than opportunistic studies (Tyack et al. 2003). Tag-based controlled studies are seen to be akin to drug trials in which both the dose and at least some aspects of the response are measurable (Tyack et al. 2003, Nowacek et al. 2007). However, unlike drug trials, the exposure history and life history of the subjects are usually completely unknown, while sampling of the pre- and postexposure behaviour and the context of the subject are limited to a few hours. There is also little control over extraneous factors such as other noise sources, prey availability, or social interactions (Miller et al. 2009), and additional replicates are needed to detect a response in the face of these incognita (McGregor 2000). An additional consideration in both opportunistic and controlled studies is that some individuals (e.g. calves, mothers with calves) may not be permitted for tagging or may be difficult to tag, biasing the study population.

The lack of data defining acceptable exposure levels for most marine mammals has created an urgency for noise effect studies to resolve mitigation policy (Hastings 2008). This has led some industry, academic and governmental groups, associated with underwater noise sources, to fund and participate in sound effect studies (Richardson et al. 1986, McCauley et al. 2000, Miller et al. 2000, Madsen et al. 2006). In doing so, a premium may be placed on results that are directly applicable to policy development, resulting in a desire for focused experiments in relevant locations and using the actual sound source that will be subject to regulation. On the face of it, these seem sensible criteria (Tyack et al. 2003), but they may impact the effectiveness of the study. The use of a high-powered sound source deployed from a dedicated ship greatly increases the expense of the study and reduces flexibility in scheduling, both of which reduce the number of replicates (Miller et al. 2009). Uncertainty about the source level or radiation pattern make it difficult to achieve the target exposure on a tagged animal, while guaranteeing that other nearby animals are exposed within permitted levels (Tyack et al. 2003). Use of a high-power sound source also leads to incidental exposure of animals over a large area, raising the issues of pseudo-replication and habituation if replicates are performed serially (Miller et al. 2009). Likewise, performing experiments in areas relevant to an industry increases the risk of encountering animals that have been exposed to similar sounds previously and so may have a modified response. Thus, the benefits of such directed noise effect studies must be weighed against the quality and general applicability of the science that can be achieved. 


\section{Significance of results}

The detailed high-resolution data collected by multisensor acoustic tags can greatly amplify the power of sound exposure studies (Burgess et al. 1998, Costa et al. 2003, Nowacek et al. 2004, Miller et al. 2009). However, to take advantage of these devices, experiments must be matched carefully to the behaviour of the species and the capabilities of the tags, often limiting the breadth of hypotheses that can be posed. The number of useful replicates may be dictated more by budget, and factors like those described above, than by experimental design (Miller et al. 2009), encouraging an exploratory approach to data analysis. The paucity of results relevant to policy-making can lead to overinterpretation of studies with few replicates or narrow applicability, a problem exacerbated by the difference in time scales between the short-term response studies currently achievable with acoustic tags and the longterm population-level effects usually sought in policymaking (NRC 2005). Given the gaps in our understanding of the life history of most marine mammals, it is often difficult to assess the long-term significance of a short-term response (Bejder et al. 2006), and the presence, or absence, of a detectable short-term response may have little to do with the long-term effects of a disturbance (Beale \& Monaghan 2004). For example, frequent disturbance might gradually reduce fitness in reproductive females due to a small reduction in foraging efficiency, yet this sub-population may not show a robust short-term response when constrained by the nutritional demands and limited flight capacity of a calf. On the other hand, a flight response by a healthy single animal might be enabled by an abundance of prey and an extensive habitat. Given this, tag-based sound effect studies will be most effective when combined with long-term studies that provide a context and can help in framing hypotheses and in interpreting short-term data (Bejder et al. 2006). An improved understanding of the energetics, habitat choice, foraging efficiency and use of sound by marine animals, using both observational and experimental techniques like those reviewed in the present paper, are prerequisites for predicting the long-term impacts of changes in the marine environment and for developing meaningful protection policies (NRC 2005).

\section{CONCLUSIONS}

In their first decade, acoustic recording tags have contributed significant insights into marine mammal ecology, physiology, behaviour and sound production, with important implications for conservation. The high acquisition rate and relatively short recording times of acoustic tags mean that data are collected in fundamentally different time and spatial scales than they are with traditional bio-telemetry (e.g. depth and positioning sensing) tags. Techniques to examine this dense data are beginning to emerge, along with applications and experiment designs that play to the strength of the technology. Particularly promising are integrated studies combining acoustic tags, tracking and prey-field mapping to explore how these large predators interact with their ecosystem. A crucial step for acoustic tags will be to lengthen attachment and recording durations to the scale of weeks if there is sufficient evidence that doing so has minimal impact on the host animal. Dense data over this time scale is needed to describe the dynamic behaviour of marine mammals and to appreciate the potential long-term implications of changes and disturbances in the marine environment on their ecology.

Acknowledgements. The authors gratefully acknowledge the efforts of all those involved in the development of acoustic tags and recording methods for marine mammals. Special thanks to T. Hurst, A. Shorter, A. Bocconcelli, M. Moore, P. Tyack, and everyone involved in the DTAG project over the years. P.T.M. thanks N. U. Kristiansen for collaboration during development of the AU sperm whale tag. Conversations with M. Wahlberg, P. Miller, B. Møhl, P. Tyack and E. Terray helped to develop the ideas in the present paper. Funding for the review came from the National Oceanographic Partnership Program. The DTAG work described here has been supported by the Mineral Management Service, Office of Naval Research, Strategic Environmental Research and Development Program, Navy N45, Packard Foundation and others.

\section{LITERATURE CITED}

Aguilar Soto N, Johnson M, Madsen PT, Tyack PL, Bocconcelli A, Borsani F (2006) Does intense ship noise disrupt foraging in deep diving Cuvier's beaked whales (Ziphius cavirostris)? Mar Mamm Sci 22:690-699

Aguilar Soto N, Johnson M, Madsen P, Diaz F, Dominguez Tejeda I, Brito A, Tyack P (2008) Cheetahs of the deep sea: deep foraging sprints in short finned pilot whales off Tenerife (Canary Islands). J Anim Ecol 77:936-947

Akamatsu T, Wang D, Nakamura K, Wang K (1998) Echolocation range of captive and free-ranging baiji (Lipotes vexillifer), finless porpoise (Neophocaena phocaenoides), and bottlenose dolphin (Tursiops truncatus). J Acoust Soc Am 104:2511-2516

> Akamatsu T, Matsuda A, Suzuki S, Wang D and others (2005a) New stereo acoustic data logger for free-ranging dolphins and porpoises. J Mar Tech Soc 39:3-9

> Akamatsu T, Wang D, Wang K (2005b) Off-axis sonar beam pattern of free-ranging finless porpoises measured by a stereo pulse event data logger. J Acoust Soc Am 117: 3325-3330

Akamatsu T, Wang D, Wang K, Naito Y (2005c) Biosonar behaviour of free-ranging porpoises. Proc R Soc Lond B Biol Sci 272:797-801

- Akamatsu T, Teilmann J, Miller LA, Tougaard J and others (2007) Comparison of echolocation behaviour between 
coastal and riverine porpoises. Deep-Sea Res II 54: 290-297

Andrews RD, Pitman RL, Ballance LT (2008) Satellite tracking reveals distinct movement patterns for type $B$ and type $C$ killer whales in the southern Ross Sea, Antarctica. Polar Biol 31:1461-1468

$\mathrm{Au}$ WWL (1993) The sonar of dolphins. Springer-Verlag, New York

Au WWL, Benoit-Bird KJ (2003) Automatic gain control in the echolocation system of dolphins. Nature 423:861-863

Au WWL, Wursig B (2004) Echolocation signals of dusky dolphins (Lagenorhynchus obscurus) in Kaikoura, New Zealand. J Acoust Soc Am 115:2307-2313

Baird RW, Hanson MB, Dill LM (2005) Factors influencing the diving behaviour of fish-eating killer whales: sex differences and diel and interannual variation in diving rates. Can J Zool 83:257-267

Barlow J, Gisiner R (2006) Mitigating, monitoring and assessing the effects of anthropogenic sound on beaked whales. J Cetacean Res Manag 7:239-249

Barlow J, Taylor BL (2005) Estimates of sperm whale abundance in the northeastern temperate Pacific from a combined acoustic and visual survey. Mar Mamm Sci 21: 429-445

Baumgartner MF, Mate BR (2003) Summertime foraging ecology of North Atlantic right whales. Mar Ecol Prog Ser 264: 123-135

Baumgartner MF, Freitag L, Partan J, Ball K, Prada K (2008) Tracking large marine predators in three dimensions: the real-time acoustic tracking system. IEEE J Oceanic Eng 33:146-157

> Beale CM, Monaghan P (2004) Behavioural responses to human disturbance: A matter of choice? Anim Behav 68: 1065-1069

Bejder L, Samuels A, Whitehead A, Gales N (2006) Interpreting short-term behavioural responses to disturbance within a longitudinal perspective. Anim Behav 72:1149-1158

Benoit-Bird KJ, Au WWL (2003) Prey dynamics affect foraging by a pelagic predator (Stenella longirostris) over a range of spatial and temporal scales. Behav Ecol Sociobiol 53:364-373

Bies DA, Hanson CH (1996) Engineering noise control, 2nd edn. E\&FN Spon, London

Blackwell SB, Haverl CA, Le Boeuf BJ, Costa DP (1999) A method for calibrating swim-speed recorders. Mar Mamm Sci 15:894-905

Blomqvist C, Amundin M (2004) An acoustic tag for recording directional pulsed ultrasounds aimed at free-swimming bottlenose dolphins (Tursiops truncatus). Aquat Mamm 30:345-356

Bowen WD (1997) Role of marine mammals in aquatic ecosystems. Mar Ecol Prog Ser 158:267-274

Burgess WC (2008) A miniature acoustic recording tag: applications to assess marine wildlife response to sound. Report GS0105A-0801, Greenridge Sciences, Santa Barbara, CA

Burgess WC, Tyack PL, Le Boeuf BJ, Costa DP (1998) A programmable acoustic recording tag and first results from free-ranging northern elephant seals. Deep-Sea Res 45: $1327-1351$

Calambokidis J, Schorr GS, Steiger GH, Francis J and others (2007) Insights into the underwater diving, feeding, and calling behavior of blue whales from a suction-cup attached video-imaging tag (CRITTERCAM). J Mar Tech Soc 41:19-29

Cooke SJ, Hinch SG, Wikelski M, Andrews RD, Kuchel LJ, Wolcott TG, Butler PJ (2004) Biotelemetry: a mechanistic approach to ecology. Trends Ecol Evol 19:334-341
Costa DP, Crocker DE, Gedamke J, Webb PM and others (2003) The effect of a low-frequency sound source (acoustic thermometry of the ocean climate) on the diving behavior of juvenile northern elephant seals, Mirounga angustirostris. J Acoust Soc Am 113:1155-1165

Cox TM, Ragen TJ, Read AJ, Baird RW and others (2006) Understanding the impacts of anthropogenic sound on beaked whales. J Cetacean Res Manag 7:177-187

Davis RW, Fuiman LA, Williams TM, Collier SO and others (1999) Hunting behavior of a marine mammal beneath the Antarctic fast ice. Science 283:993-996

Davis RW, Jaquet N, Gendron D, Markaida U, Bazzino G, Gilly W (2007) Diving behavior of sperm whales in relation to behavior of a major prey species, the jumbo squid, in the Gulf of California, Mexico. Mar Ecol Prog Ser 333: 291-302

Deecke VB, Ford JKB, Slater PJB (2005) The vocal behaviour of mammal-eating killer whales: communicating with costly calls. Anim Behav 69:395-405

> Domenici P, Batty RS, Similä T, Ogam E (2000) Killer whales (Orcinus orcs) feeding on schooling herring (Clupea harengus ) using underwater tail-slaps: kinematic analysis of field observations. J Exp Biol 203:283-294

Ehrenberg JE, Steig TW (2002) A method for estimating the 'position accuracy' of acoustic fish tags. ICES J Mar Sci 59: 140-149

> Fletcher S, Le Boeuf BJ, Costa DP, Tyack PL, Blackwell SB (1996) Onboard acoustic recording from diving northern elephant seals. J Acoust Soc Am 100:2531-2539

Ford JKB (1991) Vocal traditions among resident killer whales Orcinus orca in coastal waters of British Columbia, Canada. Can J Zool 69:1454-1483

Fristrup KM, Harbison GR (2002) How do sperm whales catch squids? Mar Mamm Sci 18:42-54

Gannon DP, Barros NB, Nowacek DP, Read AJ, Waples DM, Wells RS (2005) Prey detection by bottlenose dolphins, Tursiops truncatus: an experimental test of the passive listening hypothesis. Anim Behav 69:709-720

Gill M, Brewer J (eds) (2008) Nonvolatile memory technologies with emphasis on flash: a comprehensive guide to understanding and using flash memory devices. IEEE Press, Piscataway, NJ

Goldbogen JA, Calambokidis J, Shadwick RE, Oleson EM, McDonald MA (2006) Kinematics of diving and lungefeeding in fin whales. J Exp Biol 209:1231-1244

- Goldbogen JA, Pyenson ND, Shadwick RE (2007) Big gulps require high drag for fin whale lunge feeding. Mar Ecol Prog Ser 349:289-301

Gordon JC (1987) The behaviour and ecology of sperm whales off Sri Lanka. PhD dissertation, University of Cambridge, Cambridge

> Gordon JC (1991) Evaluation of a method for determining the length of sperm whales (Physeter catodon) from their vocalizations. J Zool (Lond) 224:301-314

Green DM, DeFerrari HA, McFadden D, Pearse JS and others (1994) Low-frequency sound and marine mammals: current knowledge and research needs. National Academy Press, Washington, DC

Grewal M, Weill LR, Andrews AP (2001) Global positioning systems, inertial navigation, and integration. John Wiley \& Sons, New York

Griffin DR (1958) Listening in the dark: the acoustic orientation of bats and men. Cornell University Press, Ithaca, NY

Hain JHW, Carter GR, Kraus SD, Mayo CA, Winn HE (1982) Feeding behavior of the humpback whale, Megaptera novaeangliae, in the western North Atlantic. Fish Bull (Wash DC) 80:259-268 
Hanson MB (2001) An evaluation of the relationship between small cetacean tag design and attachment durations: a bioengineering approach. PhD dissertation, University of Washington, Seattle, WA

Hanson MB, Baird RW (1998) Dall's porpoise reactions to tagging attempts using a remotely-deployed suction-cup tag. Mar Tech Soc J 32:18-23

Hastings M (2008) Coming to terms with the effects of ocean noise on marine animals. Acoust Today 4:22-34

Hildebrand JA (2005) Impacts of anthropogenic sound. In: Reynolds JE, Perrin WF, Reeves RR, Montgomery S, Ragen $\mathrm{T}$ (eds) Marine mammal research: conservation beyond crisis. Johns Hopkins University Press, Baltimore, MD, p 101-123

Hindell MA, Lea MA (1998) Heart rate, swimming speed and estimated oxygen consumption of a free-ranging southern elephant seal. Physiol Zool 71:74-84

Hooker SK, Baird RW (2001) Diving and ranging behaviour of odontocetes: a methodological review and critique. Mammal Rev 31:81-105

Hooker SK, Baird RW, Al-Omari A, Gowans S, Whitehead H (2001) Behavioral reactions of northern bottlenose whales to biopsy darting and tag attachment procedures. Fish Bull (Wash DC) 99:303-308

Houser D, Martin SW, Bauer EJ, Phillips M and others (2005) Echolocation characteristics of free-swimming bottlenose dolphins during object detection and identification. J Acoust Soc Am 117:2308-2317

Insley SJ, Robson BW, Yack T, Ream RR, Burgess WC (2008) Acoustic determination of activity and flipper stroke rate in foraging northern fur seal females. Endang Species Res 4:147-155

Johnson M, Tyack PL (2003) A digital acoustic recording tag for measuring the response of wild marine mammals to sound. IEEE J Oceanic Eng 28:3-12

Johnson M, Madsen PT, Zimmer WMX, Aguilar de Soto N, Tyack PL (2004) Beaked whales echolocate on prey. Proc R Soc Lond B Biol Sci 271:383-386

> Johnson M, Madsen PT, Zimmer WMX, Aguilar de Soto N, Tyack PL (2006) Foraging Blainville's beaked whales (Mesoplodon densirostris) produce distinct click types matched to different phases of echolocation. J Exp Biol 209:5038-5050

Johnson M, Hickmott LS, Aguilar Soto N, Madsen PT (2008) Echolocation behaviour adapted to prey in foraging Blainville's beaked whale (Mesoplodon densirostris). Proc R Soc Lond B Biol Sci 275:133-139

> Jones GJ, Sayigh LS (2002) Geographic variation in rates of vocal production of free-ranging bottlenose dolphins. Mar Mamm Sci 18:374-393

Jones BA, Stanton TK, Lavery AC, Johnson M, Madsen PT, Tyack PL (2008) Classification of broadband echoes from prey of a foraging Blainville's beaked whale. J Acoust Soc Am 123:1753-1762

Kastelein RA, Jennings N, Verboom WC, De Haan D, Schooneman NM (2006) Differences in the response of a striped dolphin (Stenella coeruleoalba) and a harbour porpoise (Phocoena phocoena) to an acoustic alarm. Mar Environ Res 61:363-378

Ko D, Zeh JE (1988) Detection of migration using sound location. Biometrics 44:751-763

$>$ Kooyman GL (1972) Deep diving behaviour and effects of pressure in reptiles, birds, and mammals. Symp Soc Exp Biol 26:295-311

Leaper R, Gillespie D, Papastavrou V (2000) Results of passive acoustic surveys for odontocetes in the southern ocean. J Cetacean Res Manag 2:187-196
Lipsey MW (1989) Design sensitivity: statistical power for experimental research. Sage Publications, London

Liu CM, Hsu HW, Lee WC (2008) Compression artifacts in perceptual audio coding. IEEE Trans Audio Speech Lang Proc 16:681-695

MacLean G (2009) Weak GPS signal detection in animal tracking. J Nav 62:1-21

Madsen PT (2005) Marine mammals and noise: problems with root mean square sound pressure levels for transients. J Acoust Soc Am 117:3952-3957

> Madsen PT, Wahlberg M (2007) Recording and quantification of ultrasonic echolocation clicks. Deep-Sea Res I 54:1421-1444

> Madsen PT, Payne R, Kristiansen NU, Wahlberg M, Kerr I, Mohl B (2002) Sperm whale sound production studied with ultrasound-time-depth-recording tags. J Exp Biol 205: 1899-1906

Madsen PT, Kerr I, Payne RS (2004) Source parameter estimates of echolocation clicks from wild pygmy killer whales (Feresa attenuata). J Acoust Soc Am 116:1909-1912

> Madsen PT, Johnson M, Aguilar de Soto N, Zimmer WMX, Tyack PL (2005) Biosonar performance of foraging beaked whales (Mesoplodon densirostris). J Exp Biol 208:181-194

> Madsen PT, Johnson M, Miller PJO, Aguilar Soto N, Lynch J, Tyack P (2006) Quantitative measures of air-gun pulses recorded on sperm whales (Physeter macrocephalus) using acoustic tags during controlled exposure experiments. J Acoust Soc Am 120:2366-2379

> Marques TA, Thomas L, Ward J, DiMarzio N, Tyack PL (2009) Estimating cetacean population density using fixed passive acoustic sensors: an example with Blainville's beaked whales. J Acoust Soc Am 125:1982-1994

> Martin SW, Phillips M, Bauer EJ, Moore PW, Houser DS (2005) Instrumenting free-swimming dolphins echolocating in open water. J Acoust Soc Am 117:2301-2307

Mate B, Mesecar R, Lagerquist B (2007) The evolution of satellite-monitored radio tags for large whales: one laboratory's experience. Deep-Sea Res II 54:224-247

McCauley RD, Fewtrell J, Duncan AJ, Jenner C and others (2000) Marine seismic surveys - a study of environmental implications. APPEA 2000:692-708

> McConnell BJ, Fedak MA (1996) Movements of southern elephant seals. Can J Zool 74:1485-1496

McGregor PK, Catchpole CK, Dabelsteen T, Falls JB and others (1992) Design and interpretation of playback: the Thornbridge Hall NATO ARW consensus. In: McGregor PK (ed) Playback and studies of animal communication. Plenum Press, New York, p 1-9

> McGregor PK (2000) Playback experiments: design and analysis. Acta Ethol 3:3-8

Mellinger D, Barlow J (2003) Future directions for acoustic marine mammal surveys: stock assessment and habitat use. NOAA OAR Special Report, Contribution No. 2557, NOAA/PMEL, Springfield, VA

Mellinger DK, Stafford KM, Moore SE, Dziak RP, Matsumo H (2007) An overview of fixed passive acoustic observation methods for cetaceans. Oceanography (Wash DC) 20:36-45

> Meyer CG, Burgess WC, Papastamatiou YP, Holland KN (2007) Use of an implanted sound recording device (Bioacoustic Probe) to document the acoustic environment of a blacktip reef shark (Carcharhinus melanopterus). Aquat Living Resour 20:291-298

Miller PJO (2002) Mixed-directionality of killer whale stereotyped calls: A direction of movement cue? Behav Ecol Sociobiol 52:262-270

Miller LA, Pristed J, Mohl B, Surlykke A (1995) The click sounds of narwhals (Monodon monoceros) in Inglefield Bay, Northwest Greenland. Mar Mamm Sci 11:491-502 
Miller PJO, Biassoni N, Samuels A, Tyack PL (2000) Whale songs lengthen in response to sonar. Nature 405:903

Miller PJO, Johnson M, Tyack PL (2004a) Sperm whale behaviour indicates the use of echolocation click buzzes 'creaks' in prey capture. Proc R Soc Lond B Biol Sci 271: 2239-2247

> Miller PJO, Johnson M, Tyack PL, Terray EA (2004b) Swimming gaits, passive drag and buoyancy of diving sperm whales Physeter macrocephalus. J Exp Biol 207:1953-1967

Miller PJO, Shapiro AD, Tyack PL, Solow AR (2004c) Calltype matching in vocal exchanges of free-ranging resident killer whales, Orcinus orca. Anim Behav 67:1099-1107

Miller PJO, Aoki K, Rendell LE, Amano M (2008) Stereotypical resting behavior of the sperm whale. Curr Biol 18: $\mathrm{R} 21-\mathrm{R} 23$

> Miller PJO, Johnson M, Madsen PT, Biassoni N, Quero M, Tyack PL (2009) Using at-sea experiments to study the effects of airguns on the foraging behavior of sperm whales in the Gulf of Mexico. Deep-Sea Res I 56: 1168-1181

Mitani Y, Sato K, Ito S, Cameron MF, Siniff DB, Naito Y (2003) A method for reconstructing three-dimensional dive profiles of marine mammals using geomagnetic intensity data: results from two lactating Weddell seals. Polar Biol 26:311-317

- Mitani Y, Watanabe Y, Sato K, Cameron MF, Naito Y (2004) 3D diving behavior of Weddell seals with respect to prey accessibility and abundance. Mar Ecol Prog Ser 281:275-281

Miyamoto Y, Sakai T, Furusawa M, Naito Y (2004) Development of high-frequency micro-echosounder. Fish Sci 70: 381-388

Møhl B, Wahlberg M, Madsen PT, Heerfordt A, Lund A (2003) The monopulsed nature of sperm whale clicks. J Acoust Soc Am 114:1143-1154

> Nowacek DP, Johnson MP, Tyack PL (2004) North Atlantic right whales (Eubalaena glacialis) ignore ships but respond to alerting stimuli. Proc R Soc Lond B Biol Sci 271:227-231

> Nowacek DP, Thorne LH, Johnston DW, Tyack PL (2007) Responses of cetaceans to anthropogenic noise: a review and evaluation of potential behavioural and physiological consequences. Mammal Rev 37:81-115

NRC (National Research Council) (2005) Marine mammal populations and ocean noise: determining when noise causes biologically significant effects. National Academies Press, Washington, DC

> Oleson EM, Calambokidis J, Burgess WC, McDonald MA, LeDuc CA, Hildebrand JA (2007) Behavioral context of call production by eastern North Pacific blue whales. Mar Ecol Prog Ser 330:269-284

Oswald JN, Barlow J, Norris T (2003) Acoustic identification of nine delphinid species in the eastern tropical Pacific Ocean. Mar Mamm Sci 19:20-37

Pavlov VV, Wilson RP, Lucke K (2007) A new approach to tag design in dolphin telemetry: computer simulations to minimise deleterious effects. Deep-Sea Res II 54:404-414

Popper AN, Fewtrell J, Smith ME, McCauley RD (2003) Anthropogenic sound: effects on the behavior and physiology of fishes. Mar Tech Soc J 37:35-40

Richardson WJ, Wursig B, Greene CR Jr (1986) Reactions of bowhead whales, Balaena mysticetus, to seismic exploration in the Canadian Beaufort Sea. J Acoust Soc Am 79: $1117-1128$

Richardson WJ, Greene CR Jr, Malme CI, Thomson DH (1995) Marine mammals and noise. Academic Press, San Diego, CA

Ridgway SH, Carder DA, Kamolnick T, Smith RR, Schlundt CE, Elsberry WR (2001) Hearing and whistling in the deep sea: depth influences whistle spectra but does not attenu- ate hearing by white whales (Delphinapterus leucas) (Odontoceti, Cetacea). J Exp Biol 204:3829-3841

Rittenmyer KM, Schulze WA (1999) Hydrophones. In: Wiley's encyclopedia of electrical and electronic engineering. John Wiley, New York, p 402-419

Robinson T (1994) SHORTEN: simple lossless and nearlossless waveform compression. Technical Report CUED/ F-INFENG/TR.156, Cambridge University Engineering Department, Cambridge

Ropert-Coudert Y, Wilson RP (2005) Trends and perspectives in animal-attached remote sensing. Front Ecol Environ 3: 437-444

Schau HC, Robinson AZ (1987) Passive source localization employing intersecting spherical surfaces from timeof-arrival differences. IEEE Trans Acoust Speech Signal Process 35:1223-1225

Schneider K, Baird RW, Dawson S, Visser I, Childerhouse S (1998) Reactions of bottlenose dolphins to tagging attempts using a remotely-deployed suction-cup tag. Mar Mamm Sci 14:316-324

Schusterman RJ, Kastak D, Levenson DH, Reichmuth CJ, Southall BL (2000) Why pinnipeds don't echolocate. J Acoust Soc Am 107:2256-2264

Shepard ELC, Wilson RP, Liebsch N, Quintana F, Laich AG, Lucke K (2008) Flexible paddle sheds new light on speed: a novel method for the remote measurement of swim speed in aquatic animals. Endang Species Res 4:157-164

Simpson SD, Meekan M, Montgomery J, McCauley R, Jeffs A (2005) Homeward Sound. Science 308:221

Soldevilla MS, Henderson EE, Campbell GS, Wiggins SM, Hildebrand JA (2008) Classification of Risso's and Pacific white-sided dolphins using spectral properties of echolocation clicks. J Acoust Soc Am 124:609-624

Southall B, Bowles AE, Ellison WT, Finneran JJ and others (2007) Marine mammal noise exposure criteria: initial scientific recommendations. Aquat Mamm 33:411-521

Spiesberger JL, Fristrup KM (1990) Passive localization of calling animals and sensing of their acoustic environment using acoustic tomography. Am Nat 135:107-153

Stafford KM, Fox CG, Clark DS (1998) Long-range acoustic detection and localization of blue whale calls in the northeast Pacific Ocean. J Acoust Soc Am 104:3616-3625

Stafford KM, Moore SE, Fox CG (2005) Diel variation in blue whale calls recorded in the eastern tropical Pacific. Anim Behav 69:951-958

Stimpert AK, Wiley DN, Au WWL, Johnson M, Arsenault R (2007) 'Megapclicks': acoustic click trains and buzzes used during nighttime foraging of humpback whales (Megaptera novaeangliae). Biol Lett 3:467-470

Teloni V, Johnson M, Miller PJO, Madsen PT (2008) Shallow food for deep divers: dynamic foraging behavior of male sperm whales in a high latitude habitat. J Exp Mar Biol Ecol 354:119-131

> Thode A (2004) Tracking sperm whale (Physeter macrocephalus) dive profiles using a towed passive acoustic array. J Acoust Soc Am 116:245-253

Tyack PL (2000) Functional aspects of cetacean communication. In: Mann J, Connor RC, Tyack PL, Whitehead H (eds) Cetacean societies: field studies of dolphins and whales. University of Chicago Press, Chicago, IL, p 270-307

Tyack PL, Clark CW (2000) Communication and acoustic behavior of dolphins and whales. In: Au WWL, Popper AN, Fay RR (eds) Hearing by whales and dolphins. Springer-Verlag, New York, p 156-224

Tyack PL, Gordon JC, Thompson P (2003) Controlled exposure experiments to determine the effects of noise on marine mammals. Mar Tech Soc J 37:41-53 
Tyack PL, Johnson M, Aguilar de Soto N, Sturlese A, Madsen PT (2006) Extreme diving of beaked whales. J Exp Biol 209:4238-4253

> Van Parijs SM, Smith J, Corkeron PJ (2002) Using calls to estimate the abundance of inshore dolphins: a case study with Pacific humpback dolphins Sousa chinensis. J Appl Ecol 39:853-864

Wahlberg M, Mohl B, Madsen PT (2001) Estimating source position accuracy of a large-aperture hydrophone array for bioacoustics. J Acoust Soc Am 109:397-406

Ward J, Morrissey RP, Moretti DJ, DiMarzio N and others (2008) Passive acoustic detection and localization of Mesoplodon densirostris (Blainville's beaked whale) vocalizations using distributed bottom-mounted hydrophones in conjunction with a digital tag (DTAG) recording. Can Acoust 36:60-73

Ware C, Arsenault R, Plumlee M, Wiley D (2006) Visualizing the underwater behavior of humpback whales. IEEE Comput Graph Appl 26:14-18

Watkins WA, Schevill WE (1975) Sperm whales (Physeter catodon) react to pingers. Deep-Sea Res I 22:123-129

Watkins WA, Schevill WE (1976) Right whale feeding and baleen rattle. J Mammal 57:58-66

Watkins WA, Daher MA, Fristrup KM, Howald TJ (1993) Sperm whales tagged with transponders and tracked underwater by sonar. Mar Mamm Sci 9:55-67

Watwood SL, Miller PJO, Johnson MP, Madsen PT, Tyack PL (2006) Deep-diving foraging behavior of sperm whales (Physeter macrocephalus). J Anim Ecol 75:814-825

Weilgart LS, Whitehead H (1990) Vocalizations of the North Atlantic pilot whale (Globicephala melas) as related to behavioral contexts. Behav Ecol Sociobiol 26:399-402

Weilgart LS, Whitehead H (1997) Group-specific dialects and geographical variation in coda repertoire in South Pacific sperm whales. Behav Ecol Sociobiol 40:277-285

Werth A (2000) A kinematic study of suction feeding and associated behavior in the longfinned pilot whale Globicephala melas. Mar Mamm Sci 16:299-314

Submitted: August 15, 2008; Accepted: August 3, 2009
Wiggins SM (2003) Autonomous acoustic recording packages (ARPs) for long-term monitoring of whale sounds. Mar Tech Soc J 37:13-22

Williams TM, Fuiman LA, Horning M, Davis RW (2004) The cost of foraging by a marine predator, the Weddell seal Leptonychotes weddelli: pricing by the stroke. J Exp Biol 207:973-982

Wilson RP, Wilson MP (1988) Dead reckoning: a new technique for determining penguin movements at sea. Meeresforsch 32:155-158

> Wilson RP, Grant WS, Duffy DC (1986) Recording devices on free-ranging marine animals: Does measurement affect foraging performance? Ecology 67:1091-1093

- Wilson RP, Liebsch N, Davies IM, Quintana F and others (2007) All at sea with animal tracks; methodological and analytical solutions for the resolution of movement. DeepSea Res 54:193-210

Wright AJ, Aguilar Soto N, Baldwin AL, Bateson M and others (2007) Do marine mammals experience stress related to anthropogenic noise? Int J Comp Psychol 20:274-316

- Zimmer WMX, Johnson MP, D'Amico A, Tyack PL (2003) Combining data from a multisensor tag and passive sonar to determine the diving behavior of a sperm whale (Physeter macrocephalus). IEEE J Oceanic Eng 28:13-28

Zimmer WMX, Johnson MP, Madsen PT, Tyack PL (2005a) Echolocation clicks of free-ranging Cuvier's beaked whales (Ziphius cavirostris). J Acoust Soc Am 117:3919-3927

Zimmer WMX, Madsen PT, Teloni V, Johnson MP, Tyack PL (2005b) Off-axis effects on the multipulse structure of sperm whale usual clicks with implications for sound production. J Acoust Soc Am 118:3337-3345

- Zimmer WMX, Tyack PL, Johnson MP, Madsen PT (2005c) Three-dimensional beam pattern of regular sperm whale clicks confirms bent-horn hypothesis. J Acoust Soc Am 117:1473-1485

Zimmer WMX, Harwood J, Tyack PL, Johnson M, Madsen PT (2008) Passive acoustic detection of deep diving beaked whales. J Acoust Soc Am 124:2823-2832

Proofs received from author(s): October 28, 2009 